\title{
Haematological \& Inflammatory Markers in Septicaemia and Its Prognostic Implications in Okhla Industrial Area
}

\author{
Juhi Aggarwal ${ }^{1}$, Swati Singh², Walia Murshida Huda³, Mayur Kumar4, Jagmohan Dhakad ${ }^{5}$, Yogesh Yadav ${ }^{6}$ \\ 1,3 Department of Biochemistry, Santosh Medical College and Hospital, Ghaziabad, Uttar Pradesh, India. \\ ${ }^{2}$ Department of Pathology, Santosh Medical College and Hospital, Ghaziabad, Uttar Pradesh, India. \\ ${ }^{4}$ Department of Biochemistry, ESIC Hospital, Okhla Industrial Area, Delhi, India. ${ }^{5}$ Department of Community \\ Medicine, NSCB Medical College, Jabalpur, Madhya Pradesh, India. ${ }^{6}$ Department of Anatomy, Santosh \\ Medical College and Hospital, Ghaziabad, Uttar Pradesh, India.
}

\section{ABSTRACT}

\section{BACKGROUND}

Sepsis remains an important cause of hospitalisation and mortality worldwide among patients admitted in intensive care units (ICU). Due to increasing mortality and morbidity of sepsis early diagnosis and treatment are essential. This can be achieved with the help of biomarkers-haematological and inflammatory i.e., C-reactive protein (CRP) and pro calcitonin (PCT). They are found to be highly sensitive and useful markers for early detection and management of sepsis.

\section{METHODS}

This is a cross-sectional study conducted from May 2019 to March 2020 in the Department of Biochemistry, ESI Hospital, Okhla. A total of 104 subjects were recruited for the study. Of them, 52 subjects were healthy controls, and 52 cases were ICU patients. Samples were taken to evaluate differential leucocyte count (DLC), red cell distribution width standard deviation (RDW SD), platelet count (PLT), absolute neutrophil count (ANC) and platelet crit as haematological markers whereas Creactive protein, fibrinogen and pro calcitonin indices were chosen as inflammatory markers.

\section{RESULTS}

There was significant increase in the TLC $(21583.51 \pm 2240.36)$, total neutrophil count (7889.48 \pm 1482.83$)$, immature neutrophil $(2.97 \pm 1.67)$, fibrinogen levels (518.07 \pm 66.74$)$, CRP $(0.048 \pm 0.01)$ and pro calcitonin levels $(0.062 \pm 0.22)$ of the cases as compared to the healthy controls. The platelet count was observed to be higher in healthy subjects as compared to the patients in ICU.

\section{CONCLUSIONS}

The study results showed that clinical examination along with laboratory testing which include hematologic and inflammatory biomarkers is the most effective combination of parameters for rapidly and accurately predicting or diagnosing sepsis in a critically ill patient.

\section{KEY WORDS}

Sepsis, Haematological, Inflammatory, CRP, PCT, Fibrinogen
Corresponding Author: Dr. Yogesh Yadav, Professor, Santosh Medical College and Hospital, Ghaziabad, Uttar Pradesh, India. E-mail:yogeshyadav@msn.com

DOI: $10.14260 / \mathrm{jemds} / 2021 / 103$

How to Cite This Article:

Aggarwal J, Singh S, Huda WM, et al. Haematological \& inflammatory markers in septicaemia and its prognostic implications in Okhla industrial area. J Evolution Med Dent Sci 2021;10(08):469-473, DOI: 10.14260/jemds/2021/103

Submission 29-09-2020,

Peer Review 23-12-2020,

Acceptance 30-12-2020,

Published 22-02-2021.

Copyright (C) 2021 Juhi Aggarwal et al. This is an open access article distributed under Creative Commons Attribution License [Attribution 4.0 International (CC BY 4.0)] 


\section{BACKGROUND}

Sepsis remains an important cause of hospitalisation and mortality worldwide among patients admitted in intensive care units. ${ }^{1}$ In a 5 year prospective study conducted by Sharmila Chatterjee et al. it was found that ICU mortality was $56 \%$ in patients admitted with sepsis. ${ }^{2}$ Sepsis can be defined as a life threatening organ malfunction caused by the dys regulated host response to an infection. ${ }^{3}$ It is based on three cardinal symptoms-altered mental status, fast respiratory rate ( $>22$ breaths / minute) and low blood pressure ( $\leq 100 \mathrm{~mm} \mathrm{Hg}$ systolic). There are three levels of severity within sepsis which are identified as sepsis, severe sepsis, and septic shock which depends upon increasing organ system involvement and coinciding mortality rates. ${ }^{4}$ Early diagnosis and treatment is very important as mentioned in a study by Kumar et al. stating that mortality increases by 8 percent each hour if treatment is delayed. ${ }^{5}$ Organ dysfunction or failure was assessed with the help of SOFA (Sepsis related Organ Failure Assessment) score which was developed by Vincent et al. ${ }^{6}$ SOFA was designed to describe the sequence of complications in a critically ill patient and thus, helped to evaluate morbidity in sepsis. This score included six physiological systems (respiratory, coagulation, hepatic, cardiovascular, renal and neurological) and assigned points based on the degree of organ system dysfunction. A SOFA score of $\geq 2$ and a documented or suspected infection is considered as sepsis. Though newer guidelines have changed however, this SOFA score is still used in cases of proven or suspected infection. Due to increasing mortality and morbidity of sepsis early diagnosis and treatment is essential for the clinician. Positive blood or body fluid culture requires 24 to 48 hours to develop and many at times it can be falsely negative. Hence, there is an urgent need for biomarkers-inflammatory and haematological for early diagnosis of sepsis.

Following any infection there is a phase of hyperinflammatory response, which is called systemic inflammatory response syndrome (SIRS) which either may resolve or if further complicated can progress to severe sepsis. Whenever body is affected by harmful stimulus like infection and trauma, we can see release of pro inflammatory cytokines like interleukin 6, interleukin 1, TNF $\alpha$ and gamma interferon. ${ }^{7}$ These cytokines trigger the liver to release acute phase proteins such as CRP and fibrinogen. Fibrinogen is elevated in initial stages of sepsis. ESR determines the rate at which RBC by virtue of its rouleaux formation settles down when placed in a vertical tube for an hour and indirectly measures the amount of fibrinogen, hence, increased levels of fibrinogen can increase ESR, which generally increases within 24 to 48 hours. Acute inflammation due to infectious diseases, tissue trauma, ischemia or tumour can lead to high ESR. ${ }^{8}$ CRP is a highly sensitive marker of inflammation. It was first discovered by Tillet and Francis in 1930 when they showed it reacted to the C-polysaccharide of Streptococcus pneumoniae in patients with pneumococcal pneumonia. Normal range is 2 to $10 \mathrm{mg} / \mathrm{l}$ and its level starts to rise after 4 to 6 hours and peaks by 36 to 50 hours and can increase 100 to 1000 fold during acute inflammation. ${ }^{9}$ PCT was first described in 1993 as a useful biomarker of sepsis and infection. ${ }^{10}$ Normal value of PCT is less than $0.1 \mathrm{ng} / \mathrm{ml}$. Higher values of PCT over $0.5 \mathrm{ng} / \mathrm{ml}$ is highly suggestive of bacterial infection and antibiotics are recommended. The pro inflammatory cytokines like IL6, IL1 and TNF- $\alpha$ like CRP and fibrinogen stimulates the release of
PCT but gamma interferon which is produced in viral infection does not stimulate PCT release, thereby proving PCT to be a marker highly suggestive of bacterial infections only. ${ }^{11}$ PCT is detectable within 3 to 4 hours of an infection and peaks within 6 to 24 hours making it a marker superior than CRP in sepsis.

Endothelial dysfunction plays a key role in the pathogenesis of sepsis and is responsible for haematological changes which occur during sepsis. The endothelial injury generally occurs after entry of bacterial endotoxins or due to the effect of pro inflammatory cytokines and thus, can further lead to micro vascular coagulopathy and acute organ damage. ${ }^{12}$ In sepsis we can find alterations in the property of red cell membrane which can lead to decrease in oxygen carrying capacity and change in mechanical properties of red cell disrupting the microcirculation and decreasing the oxygen delivery to the tissue. In early sepsis there is decrease in the red cell deformability which can decrease blood flow and increasing time for cell to transit the microcirculation. ${ }^{13}$

The most common laboratory finding includes anaemia with fall in haematocrit (HCT) values, low RBC count or low haemoglobin concentration, thereby decreasing oxygen carrying capacity. Neutrophilic leucocytosis is also commonly observed. Neutropenia is more prevalent in paediatric age group with severe sepsis. ${ }^{14}$ Peripheral smear include neutrophilia with toxic granulation and Dohle bodies, increased proportions of non-segmented or band neutrophils and circulating immature granulocytes (metamyelocytes and myelocytes). ${ }^{15}$ Thrombocytopenia is seen in cases of severe sepsis which is a marker of hematologic organ dysfunction. ${ }^{16}$ In 20 to $40 \%$ cases of ICU patients platelet count was found to be less than $100 \times 10^{9} / \mathrm{L}$ and sepsis was found to be the major reason for thrombocytopenia. ${ }^{17}$ There can be signs of disseminated intravascular coagulation (DIC) which can include combination of thrombocytopenia along with prolongation of prothrombin time (PT) with international normalised ratio (INR) and activated partial thromboplastin time (APTT) in severe sepsis. Factor VIII is decreased in severe sepsis and elevated in liver disease. ${ }^{18}$

Thus, the present study was conducted to investigate the significance of the various haematological and inflammatory markers to ascertain their role in early diagnosis and management of the patients admitted in ICU.

\section{METHODS}

The present study is a cross-sectional study conducted from May 2019 to March 2020 in the Department of Biochemistry, ESI Hospital, Okhla. A total of 104 subjects were recruited for the study. Informed written consent was obtained from them. Of them, 52 subjects were healthy controls, and 52 cases were ICU patients.

\section{Sampling Method}

Inclusion criteria for ICU admission were threatened airway, respiratory arrests, pulse rate $<40$ or $>140$ beats / min, sudden fall in level of consciousness, repeated or prolonged seizures, deranged arterial blood gas (ABG), respiratory rate $\geq$ 40 or $\leq 8$ breathes / min. Exclusion criteria included: age below 23 years; known pregnancy patients; primary cases of trauma, burns, active seizure, acute cerebral vascular accident, 
acute coronary syndrome, status asthmaticus, cardiac arrhythmias, active gastrointestinal bleeding, drug overdose; requirement for immediate surgery; active chemotherapy; and haematological malignancy.

The various assumptions used in sample size calculation are

1. Power - $85 \%$

2. Effect size -0.5

3. Tails - Two

4. 3 allocation ratio $-1: 1: 1$

A detailed clinical history including age, sex, occupation, socio-economic status, duration of diabetes and any associated risk factor contributing for the illness was elicited from the subjects. Under all aseptic precautions, blood samples $(5 \mathrm{ml})$ were drawn by venipuncture and collected in EDTA and plain tubes respectively to analyse for haematological parameters like differential leucocyte count, red cell distribution width standard deviation, platelet count, absolute neutrophil count and platelet crit whereas C-reactive protein, fibrinogen and pro calcitonin indices were chosen as inflammatory markers.

\section{Statistical Analysis}

The sample size calculations were done on $\mathrm{G}$ power software version 3.1.9.2. For difference between two independent means. Student t-test was applied to calculate mean standard deviation and P-value.

\begin{tabular}{|c|c|}
\hline \multicolumn{2}{|c|}{ RESULTS } \\
\hline Variables & Mean \pm SD \\
\hline TLC cumm & $21583.51 \pm 2240.36$ \\
\hline TNC cumm & $7889.48 \pm 1482.83$ \\
\hline Band cells $\%$ & $2.97 \pm 1.67$ \\
\hline PLT count lac / cumm & $163.77 \pm 29.035$ \\
\hline NUC.RBC count & $0.06 \pm 0.01$ \\
\hline Fibrinogen (MG / DL) & $518.07 \pm 66.74$ \\
\hline CRP (MG / DL) & $0.048 \pm 0.01$ \\
\hline PCT (NG / ML) & $0.062 \pm 0.22$ \\
\hline Table 1. Haematological & Iarkers in ICU Patients \\
\hline
\end{tabular}

\begin{tabular}{|cc|}
\hline Variables & Mean \pm SD \\
TLC cumm & $9154.74 \pm 1934.90$ \\
TNC cumm & $3876.629 \pm 1073.24$ \\
Band cells \% & $0.11 \pm 0.02$ \\
PLT Count lac / cumm & $21471.74 \pm 22860.44$ \\
NUC.RBC Count & $1.44 \pm 1.23$ \\
Fibrinogin (MG / DL) & $187.96 \pm 47.49$ \\
CRP (MG / DL) & $1.22 \pm 042$ \\
PCT (NG / ML) & $0.010 \pm 0.03$ \\
\hline Table 2. Haematological \& Inflammatory Markers \\
\multicolumn{2}{|c|}{ in Normal Individuals } \\
\hline
\end{tabular}

Table 1 \& Table 2 show the haematological and inflammatory markers in both ICU admitted patients and healthy controls respectively. There was significant increase in the total leucocyte count (21583.51 \pm 2240.36), total neutrophil count $(77889.48 \pm 1482.83)$, immature neutrophil (2.97 \pm 1.67$)$, fibrinogen levels (518.07 \pm 66.74$)$, CRP (1.22 \pm $042)$ and pro calcitonin levels $(0.062 \pm 0.22)$ in the cases as compared to the healthy controls. The level of platelet count was observed to be higher in the healthy subjects (21471.74 \pm
22860.44) as compared to the admitted patients in ICU $(163.77 \pm 29.035)$. The results are presented in mean \pm SD. All the biochemical and haematological parameters were compared by using unpaired t-test between cases and controls. The Pearson's correlation coefficient was calculated among the study parameters. The P-value $<0.05$ was considered significant. (Table 3)

\begin{tabular}{|cccccc|}
\hline Variables & $\begin{array}{c}\text { Septic (52) } \\
\text { Mean } \pm \text { SD }\end{array}$ & $\begin{array}{c}\text { Non-Septic (52) } \\
\text { Mean } \pm \text { SD }\end{array}$ & $\begin{array}{c}\text { t } \\
\text { Value }\end{array}$ & $\begin{array}{c}\text { P } \\
\text { Value }\end{array}$ & Conclusion \\
TLC cumm & $\begin{array}{c}21583.51 \pm \\
2240.36\end{array}$ & $9154.74 \pm 1934.90$ & 21.81 & 0.001 & Significant \\
TNC cumm & $\begin{array}{c}7889.48 \pm \\
1482.83\end{array}$ & $3876.629 \pm 1073.24$ & 11.39 & 0.001 & Significant \\
$\begin{array}{c}\text { Band cells \% } \\
\text { PLT count lac } \\
\text { / cumm }\end{array}$ & $\begin{array}{c}163.71 \pm 0.02 \\
29.035\end{array}$ & $21471.74 \pm 22860.44$ & 4.84 & 0.001 & Significant \\
$\begin{array}{c}\text { NUC.RBC } \\
\text { count }\end{array}$ & $0.06 \pm 0.01$ & $1.44 \pm 1.23$ & 17.02 & 0.001 & Significant \\
$\begin{array}{c}\text { Fibrinogen } \\
\text { (MG / DL) }\end{array}$ & $518.07 \pm 66.74$ & $187.96 \pm 47.49$ & 20.94 & 0.001 & Significant \\
$\begin{array}{c}\text { CRP (MG / } \\
\text { DL) }\end{array}$ & $1.22 \pm 042$ & $0.048 \pm 0.01$ & 16.85 & 0.001 & Significant \\
$\begin{array}{c}\text { PCT (NG / } \\
\text { ML) }\end{array}$ & $0.062 \pm 0.22$ & $0.010 \pm 0.03$ & 1.17 & 0.001 & Significant \\
\hline $\begin{array}{c}\text { Table 3. Correlation of Haematological \& Inflammatory Markers } \\
\text { between Normal Individuals and ICU Patients }\end{array}$ & \\
\hline
\end{tabular}

\section{DISCUSSION}

CRP is the most widely accepted marker of infection and inflammation and has been more used in paediatrics ${ }^{19}$ to detect any infectious or inflammatory disease. Nowadays it is more commonly used in cardiovascular or atherosclerotic conditions. ${ }^{20}$ Numerous comparative studies of CRP and PCT were conducted in diagnosing sepsis where initially PCT was found to be more sensitive and specific than CRP for identifying bacterial infection. ${ }^{21} \mathrm{~A}$ large meta-analysis done by Uzzan et al. ${ }^{22}$ collected 33 studies between April, 1996, and October, 2004, where it included 3,943 patients of sepsis and it was observed that the receiver operating characteristic (ROC) curve for PCT was much higher than CRP ( 0.78 versus 0.71). A recent meta-analysis done by Tang et al. ${ }^{23}$ that collected 30 studies showed that PCT has a low accuracy in distinguishing sepsis from SIRS. Muller et al. ${ }^{24}$ in 2007 conducted a study in patients with community acquired pneumonia, where he projected that PCT concentration helped to distinguish bacterial from viral pneumonia. In 2007 Kofoed et al. ${ }^{25}$ concluded that combined use of three or six pro inflammatory markers was more successful in accurately identifying patients with bacterial infection. Similar multi marker approach was used by Shapiro et al. ${ }^{26}$ in 2009 in diagnosing severe sepsis. A study done by Young et al.27 investigated the potentiality of PCT as a marker to diagnose septic shock in patients with acute pyelonephritis occurring secondary to ureteral calculi. It concluded that high PCT and low platelet count are high risk factors of septic shock in such cases. In a study done by Heffner AC et al. in division of critical care medicine, it was observed that more than $50 \%$ of the patients with severe sepsis have negative culture results. Hence, culture and sensitivity offer a limited prospectus in management of severe sepsis. ${ }^{28}$ In a study done by Canan Balcl ${ }^{29}$ in 2002, it was observed that PCT has the maximum specificity and sensitivity in differentiating patients with SIRS 
from sepsis. However, the best approach in early identification of sepsis would be selection of combination of markers like haematological, pro inflammatory and anti-inflammatory markers.

\section{CONCLUSIONS}

Sepsis is the leading cause of death in hospitalised patients in ICU settings. Patients with sepsis often present with nonspecific symptoms of inflammation which rapidly progress to a more severe condition if not treated. In uncontrolled cases of sepsis, acute organ dysfunction and shock may develop. Because of this rapid progression, it is of utmost importance that patients should be diagnosed and treated in a requisite time frame.

The current literature and changing guidelines demonstrate that the bedside physical examination along with laboratory testing (haematologic and inflammatory biomarkers) are the most effective combination of parameters that clinicians can rely upon to accurately predict or diagnose sepsis in a critically ill patient. We included all the readily available cost effective parameters.

\section{Limitations of the Study}

We considered blood and fluid culture reports of the patients. Since the cost of interleukin assessment was high, we couldn't incorporate the data of the same. There should be data collection of the entire tertiary health care centres in the district so as to effectively analyse it on a large scale. The future implication of the study lies in the development of better cost-effective biomarkers for early diagnosis of sepsis patients.

Data sharing statement provided by the authors is available with the full text of this article at jemds.com.

Financial or other competing interests: None.

Disclosure forms provided by the authors are available with the full text of this article at jemds.com.

\section{REFERENCES}

[1] Marshall JC, Vincent JL, Guyatt G, et al. Outcome measures for clinical research in sepsis: a report of the $2^{\text {nd }}$ Cambridge Colloquium of the International Sepsis Forum. Crit Care Med 2005;33(8):1708-16.

[2] Chatterjee S, Bhattacharya M, Todi SK. Epidemiology of adult-population sepsis in India: a single center 5 year experience. Indian J Crit Care Med 2017;21(9):573-7.

[3] Singer M, Deutschman CS, Seymour CW, et al. The third international consensus definitions for sepsis and septic shock (Sepsis-3). JAMA 2016;315(8):801-10.

[4] Dellinger RP, Carlet JM, Masur H, et al. Surving sepsis campaign guidelines for management of severe sepsis and septic shock. Crit Care Med 2004;32(3):858-73.

[5] Kumar A, Roberts D, Wood KE, et al. Duration of hypotension before initiation of effective antimicrobial therapy is the critical determinant of survival in human septic shock. Crit Care Med 2006;34(6):1589-96.
[6] Vincent JL, Moreno R, Takala J, et al. The SOFA (SepsisRelated Organ Failure Assessment) score to describe organ dysfunction/failure. On behalf of the working group on sepsis related problems of the European society of intensive care medicine. Intensive Care Med 1996;22(7):707-10.

[7] Faix JD. Biomarkers of sepsis. Crit Rev Clin Lab Sci 2013;50(1):23-36.

[8] Ahmed MS, Jadhav AB, Hassan A, et al. Acute phase reactants as novel predictors of cardiovascular disease. ISRN Inflamm 2012;2012:953461.

[9] Gabay C, Kushner I. Acute-phase proteins and other systemic responses to inflammation. $\mathrm{N}$ Engl J Med 1999;340(6):448-54.

[10] Assicot M, Gendrel D, Carsin H, et al. High serum procalcitonin concentrations in patients with sepsis and infection. Lancet 1993;341(8844):515-8.

[11] Markanday A. Acute phase reactants in infections: evidence-based review and a guide for clinicians. Open Forum Infect Dis 2015;2(3):ofv098.

[12] Vincent JL. Microvascular endothelial dysfunction: a renewed appreciation of sepsis pathophysiology. Crit Care 2001;5(2):S1-5.

[13] Baskurt OK, Gelmont D, Meiselman HJ. Red blood cell deformability in sepsis. Am J Respir Crit Care Med 1998;157(2):421-7.

[14] Funke A, Berner R, Traichel B, et al. Frequency, natural course and outcome of neonatal neutropenia. Pediatrics 2000;106(1 Pt 1):45-51.

[15] Ardron MJ, Westengard JC, Dutcher TF. Band neutrophil counts are unnecessary for the diagnosis of infection in patients with normal total leukocyte counts. Am J Clin Pathol 1994;102(5):646-9.

[16] Baughman RP, Lower EE, Flessa HC, et al. Thrombocytopenia in the intensive care unit. Chest 1993;104(4):1243-7.

[17] Mammen EF. Coagulation abnormalities in liver disease. Hematol Oncol Clin North Am 1992;6(6):1247-57.

[18] Clarke BJ, Sridhara S, Woskowska Z, et al. Consumption of plasma factor VII in a rabbit model of non-overt disseminated intravascular coagulation. Thromb Res 2002;108(5-6):329-34.

[19] Jaye DL, Waites KB. Clinical applications of c-reactive protein in pediatrics. Pediatr Infect Dis 1997;16(8):73546.

[20] Benzaquen LR, Yu H, Rifai N. High-sensitivity C-reactive protein: an emerging role in cardiovascular risk assessment. Crit Rev Clin Lab Sci 2002;39(4-5):459-97.

[21] Simon L, Gauvin F, Amre DK, et al. Serum procalcitonin and C-reactive protein levels as markers of bacterial infection: a systematic review and meta-analysis. Clin Infect Dis 2004;39(2):206-17.

[22] Uzzan B, Cohen R, Nicolas P, et al. Procalcitonin as a diagnostic test for sepsis in critically ill adults and after surgery or trauma: a systematic review and metaanalysis. Crit Care Med 2006;34(7):1996-2003.

[23] Tang BMP, Eslick GD, Craig JC, et al. Accuracy of procalcitonin for sepsis diagnosis in critically ill patients: systemic review and meta-analysis. Lancet Infect Dis 2007;7(3):210-17. 
[24] Müller B, Becker KL, Schächinger H, et al. Calcitonin precursors are reliable markers of sepsis in a medical intensive care unit. Crit Care Med 2000;28(4):977-83.

[25] Kofoed K, Andersen O, Kronborg G, et al. Use of plasma Creactive protein, procalcitonin, neutrophils, macrophage inhibitory factor, soluble urokinase-type plasminogen activator receptor and soluble triggering receptor expressed on myeloid cells- 1 in combination to diagnose infections: a prospective study. Crit Care 2007;11(2):R38.

[26] Shapiro NI, Trzeciak S, Hollander JE, et al. A prospective, multicenter derivation of a biomarker panel to assess risk of organ dysfunction, shock and death in emergency department patients with suspected sepsis. Crit Care Med 2009;37(1):96-104.
[27] Ko YH, Ji YS, Park SY, et al. Procalcitonin determined at emergency department as an early indicator of progression to septic shock in patient with sepsis associated with ureteral calculi. Int Braz J Urol 2016;42(2):270-6.

[28] Heffner AC, Horton JM, Marchick MR, et al. Etiology of illness in patients with severe sepsis admitted to the hospital from the emergency department. Clin Infect Dis 2010;50(6):814-20.

[29] BalcI C, Sungurtekin H, Gürses E, et al. Usefulness of procalcitonin for diagnosis of sepsis in the intensive care unit. Crit Care 2003;7(1):85-90. 